\title{
A business process model of inspection in remanufacturing
}

\author{
Mark Errington $^{*}$ and Stephen J Childe
}

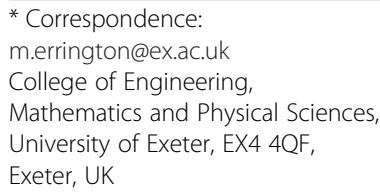

\begin{abstract}
A crucial stage of the remanufacturing process is the inspection procedure. Surveys carried out in the automotive remanufacturing sector show that the industry is concerned about the need this causes for a large amount of specialist skills. Despite this, there has been little research into what is actually involved in the inspection process and its outcomes.

This paper presents case-based research that was carried out on the inspection procedures of both electronic and mechanical product remanufacturers. It presents generic inspection process diagrams, produced using case studies in UK companies engaged in remanufacturing activities. The models provide a greater understanding of the remanufacturing inspection procedures currently used. The models were tested with additional case studies.

The paper discusses the questions raised by the improved understanding of inspection processes in remanufacturing for operations managers and outlines some questions for future research.
\end{abstract}

Keywords: Remanufacture; Inspection; Case study

\section{Background}

Early results of this research were described in [1]. Due to global warming, the Climate Change Act [2] and the imminent peaking of world oil production (as described in [3] and [4]), closer attention is being paid to the impact of manufacturing and its energy consumption on the environment. There is now an increasing amount of legislation being developed by the European Union aimed at reducing energy use as well as our impact on the environment. As more and more countries join the European Union, more manufacturers will be required to comply with this legislation. This includes the so-called producer responsibility legislation including the WEEE directive [5], End of Life Vehicles Act [6], Packaging and Packaging Waste Directive [7] and the Batteries and Accumulators Directive [8]. This legislation requires the producers of certain products to be responsible for their disposal at end of life.

Producers are not only responsible for retrieving the used products from their end users but are also responsible for recycling them whilst meeting certain minimum recycling rates. With limited room remaining in landfill sites, material recycling is often preferable to land filling; however, most of the value added during manufacture and the energy embodied in the product is lost.

(c) 2013 Errington and Childe; licensee Springer. This is an Open Access article distributed under the terms of the Creative Commons Attribution License (http://creativecommons.org/licenses/by/2.0), which permits unrestricted use, distribution, and reproduction in any medium, provided the original work is properly cited. 
In order to take back post-consumer products, it is necessary to create a reverse supply chain. In cases when this is integrated into forward manufacture, in such a way that old products are used to produce new, at any level, this leads to a 'closed-loop' supply chain [9].

Many consumer products are still working at their end of life, and there are an increasing number of companies that collect these products and return them to market both in the UK and abroad. They provide a cheap alternative to buying new products and appear to have been very successful both in not-for-profit and for-profit organisations.

Other products reach their end of life because of an accumulation of rectifiable faults, the wearing of a small number of components within a product or sometimes because of their age or amount of use. It has been shown that there has been a long tradition of remanufacturing in the auto parts industry [10]. Manufacturers in other industries such as Hewlett Packard [11], Océ [12] and Xerox [13] have started to take advantage of this way of doing business and have started to run large remanufacturing operations. It is often stated that remanufacturing is $80 \%$ more energy efficient and $60 \%$ more cost efficient than traditional manufacturing. For this reason, a large amount of attention is being paid to these types of processes by old and emerging economies alike.

Many tools now exist which can be used to evaluate the environmental and financial performance of a given product against set criteria [14-17]. The aim of these tools is to identify areas of the design that could be changed in order to enable end of life strategies to be carried out more efficiently.

There has also been a large amount of research carried out on operations management within the remanufacturing process itself. Guide et al present an analysis of the performance of different static priority rules [18], while in an earlier paper, describe the application of Goldratt's drum-buffer-rope system in a remanufacturing environment $[19,20]$. Other authors look at the use of production planning approaches in remanufacturing environments [21-31].

Reverse logistics channels themselves have also attracted a large amount of interest. Jayaraman et al. present a deterministic integer programming model which can be used to determine the optimum location for remanufacturing facilities and collection centres [9]. A similar optimisation study has been carried out by Peng ZY and Zhong [32]. Blackburn et al. discuss the need for different reverse supply chains for different models [33]. They find that depreciation rates among high-value items mean that responsive supply chains are more appropriate in some cases.

There are also some studies that look at strategies for increasing the number of cores (end-of-life items) available for remanufacture. Ray et al. present a method for determining the correct buy-back pricing strategy for used products from consumers [34]. Xiaochen et al. present a method for calculating the optimum buy-back price under certain conditions [35].

\section{Inspection and disposition decisions}

'Inspection and disposition' is one of the five main parts of a remanufacturing business [36]. Despite this, research has tended to focus largely around product design for remanufacture rather than upon the operational questions related to how a specific product is actually inspected and remanufactured. Steinhilper [37] identifies that: 
"(A) step of great importance in remanufacturing is to assess the condition of the disassembled and cleaned parts as to their reusability or reconditionability."

He goes on to state that this is done in two parts: to define the objective criteria and accepted condition characteristics and to determine how this will be assessed.

Guide and Van Wassenhove [36] describe the inspection and disposition process as follows:

"The testing, sorting and grading of returned products are labour-intensive and time-consuming tasks, but the process can be streamlined if a company subjects the returns to quality standards and uses sensors, bar codes and other technologies to automate tracking and testing."

There are many signs that the technology that is referred to in this text is beginning to be more widely used. Bosch have carried out tests with micro sensors to record data during the life of its power tool motors [38]. Their plan was to connect the tools to a data reader once they have been returned to them in order to decide whether the motors can be reused or not. At the time, similar technology was being developed as part of the Care Vision 2000 initiative to produce what they call a 'Green Port' [39].

Technology to make the inspection and disposition decision more streamlined is clearly useful in some cases. However, it is not applicable or relevant for many remanufacturing operations. These techniques are only useful to those companies who originally manufactured the product or have control over its design. Companies wishing to use such technology would have to invest with a view for a very long-term payback.

Inspection and disposition is carried out in all remanufacturing operations; however, little has been done to document current industry practices, to identify areas where savings could be made and to assess exactly which specific inspection tasks these technologies should be substituted for.

In contrast to new-product manufacture, where sampling methods are often used, remanufacturing always requires $100 \%$ inspection [40]. This is typically carried out on cores and disassembled parts as well as the finished products themselves. This is done to increase the second user's confidence in remanufactured products, and it is thought to explain why remanufactured products appear to have a better reliability than new products [40].

A comprehensive survey of manufacturers in the automotive industry was carried out in order to identify the problems the industry faces from the perspective of the remanufacturers themselves [10]. Twenty-nine percent of respondents stated that the factor which made inspection most difficult was the knowledge of the employee carrying out the work. A further $21 \%$ of respondents stated that identifying defects in cores was their main concern.

This suggests that there is a need for formal methods that can be used to simplify the processes involved in the inspection procedure. This would remove the dependence on such a high level of tacit knowledge held by the operators. As noted above, some attention has been focussed on the aspects of design that can facilitate remanufacture. In the survey, the authors note that design for remanufacturing is an issue with automotive remanufacturing [10]. 'Profit potential' and 'investment needed to 
repair' rank high as responses to how the decision to remanufacture a given product is made.

\section{Research objectives}

Researchers have established that inspection is one of the key stages in remanufacturing. The main aim of the inspection process is to determine the condition of the returned item (called the 'return' or the 'core') and select the most economically attractive re-use option [11]. Little has been done to look at the tasks involved in this process and how they can be carried out more efficiently. This paper describes work done to address this issue through case study research. It aims to establish how these processes are currently carried out as a basis for understanding and to provide a basis for analysis of potential improvements. Using the four purposes of research described by Voss et al. [41], the work is theory building since it attempts to develop new models or concepts that can help researchers and managers understand and deal with inspection. Using a broad range of cases involving different products, industries and business models but all centred on remanufacturing, the research was able to take a broad, general understanding of the issue which can be further tested and refined by future work.

The main objective of these case studies was to gain a detailed insight into the role and process of inspection operations carried out by remanufacturing firms. Despite the fact that research in this area is very immature, it is suspected that there is a huge quantity of technical expertise within the companies that in some cases have been carrying out these activities profitably for many years.

The work aimed to establish the objectives of inspection and testing at all stages of the remanufacturing process and to investigate the possibilities of gaining the same process outputs through different means.

\section{Methodology}

Case research is a very useful technique for carrying out work in immature research areas [42]. It has also been established that it can be used effectively where there is a large amount of expertise in the field that needs to be captured and formalised. Eisenhardt [43] shows how theory can be generated using case research and how it is a particularly useful method in new topic areas. Scientific rigour was ensured through following the framework for case research described by Voss et al. [41].

Discussion points were drawn from the literature and further developed using the findings from these cases. These included boundary questions to understand the characteristics of the case companies that were being studied. These included asking if the company was the original equipment manufacturers (OEM) of the products which it remanufactures and how diverse the mix of products remanufactured by each company was. The interviewees were asked to describe a remanufacturing process within their organisation and the role of inspection within it. For a full list of the questions used please see http://hdl.handle.net/10036/83380.

Cases were selected so that a broad range of industries were represented. These include OEMs and non-OEMs as well as for-profit and not-for-profit companies. Case studies were carried out with a number of companies engaged in remanufacturing in the UK. These operate different business models for a wide range of customers. Some 
carry out remanufacturing on a not-for-profit basis, and others remanufacture directly for OEMs on a large scale. The table gives some of the characteristics of the different companies that were included in the research.

It can be seen from Table 1 that the companies studied were from a wide range of industries with different products and different business objectives. The only not-for -profit organisation, CompCo, operates to give people in developing countries access to IT equipment. This adds an interesting characteristic since many of their staff work as volunteers, although this does not mean that labour is a cheap resource that may be used inefficiently. The remainder of the companies operate in a more conventional forprofit way. The prominence of automotive and defence sector remanufacturers in the study reflects the maturity of remanufacturing in these areas.

'Product type studied' describes the remanufactured component, module or product that was studied for this research. This is not necessarily the main product the company produces. Some of the cases remanufacture a large volume of products and operate in a highly competitive market while others remanufacture smaller numbers of items and are known for their expertise and competency.

Many of the cases studied were found not to describe their process as remanufacturing. For the purposes of this research, the process was considered to be remanufacturing if it met the definition developed by Ijomah and Childe [44]. This is a definition that is widely accepted in the UK remanufacturing industry. It defines a remanufacturing process as follows:

"Remanufacturing is the only process where used products are brought at least to OEM performance specification from the customer's perspective and, at the same time, are given warranties that are equal to those of equivalent new products."

Companies were approached through the UK government-funded Centre for Remanufacturing and Reuse and through university contacts. The authors note that other definitions for remanufacturing exist, and a full discussion can be found in the

Table 1 Overview of case study companies

\begin{tabular}{|c|c|c|c|c|c|}
\hline $\begin{array}{l}\text { Company } \\
\text { identifier }\end{array}$ & Customer type & Sector & $\begin{array}{l}\text { Product type } \\
\text { studied }\end{array}$ & OEM? & $\begin{array}{c}\text { For } \\
\text { profit? }\end{array}$ \\
\hline DefCo & $\begin{array}{c}\text { UK Ministry of } \\
\text { Defence }\end{array}$ & Defence equipment & $\begin{array}{l}\text { Mechanical/ } \\
\text { electronic }\end{array}$ & $\begin{array}{c}\text { OEM } \\
\text { approved }\end{array}$ & For profit \\
\hline CopyCo & Business & $\begin{array}{l}\text { Copying/Printing } \\
\text { equipment }\end{array}$ & Mechanical & OEM & For profit \\
\hline PCCO & Business & IT equipment & Electronic & Non-OEM & For profit \\
\hline GearCo & OEM & Automotive & Mechanical & $\begin{array}{c}\text { OEM } \\
\text { Approved }\end{array}$ & For profit \\
\hline ClutchCo & Business & Automotive & Mechanical & Non-OEM & For profit \\
\hline CoreCo & Remanufacturers & $\begin{array}{c}\text { Automotive core } \\
\text { broker }\end{array}$ & $\begin{array}{c}\text { Mechanical/ } \\
\text { Electronic }\end{array}$ & Non-OEM & For profit \\
\hline TurbineCo & Business & Power generation & Mechanical & OEM & For profit \\
\hline CompCo & NGOs & IT equipment & Electronic & Non-OEM & $\begin{array}{l}\text { Not for } \\
\text { profit }\end{array}$ \\
\hline MilCo & $\begin{array}{l}\text { UK Ministry of } \\
\text { Defence }\end{array}$ & Defence equipment & Mechanical & OEM & For profit \\
\hline
\end{tabular}


$\mathrm{PhD}$ thesis Business Processes and Strategic Framework for Inspection in Remanufacturing which is available to download at: http://hdl.handle.net/10036/83380.

The main difference between this definition and others is its inclusion of the word 'warranty'. The authors of this definition felt this was vital as anyone claiming that their remanufactured product was as good as or better than the new but only willing to offer a shorter warranty may not be particularly confident in their performance claim.

Company visits were carried out in mid-2006, these included a meeting with the operations managers as well as the production staff followed by a tour of the facilities being used for remanufacturing. The purpose of these visits was to gain an overall understanding of the inspection processes carried out in each of the case companies.

Complete notes were compiled directly following each visit. These consisted of background information about the company and a description of the remanufacturing and inspection processes. These included flow charts of the processes that were studied. These notes were emailed directly to those who were interviewed, for checking. The purpose of this was to ensure their internal validity and correctness. Results from case studies were triangulated through visits to the factory floor and further interviews with the production staff. After each visit, the case notes were sent to the interviewees promptly to verify their accuracy.

An analysis of the data collected through the case study meetings is presented in the following section.

\section{Results and analysis}

In this section, we present four of the cases used in the research. Two are from the automotive industry, and two are from the computer industry. The cases show that there are similarities and differences within each industry and between the industries. It will be shown later how a general model can be structured to cover all the options.

\section{GearCo}

GearCo is a remanufacturer of automotive drive trains. They remanufacture engines, transmissions and gearboxes as an OEM approved remanufacturer.

Used items are stored when received, until the arrival of an order for that type of item. When an order arrives, an initial visual inspection of the core is made for obvious damage which would make the core uneconomical to repair, for example a cracked casing. The reason for failure of a returned core is not always obvious, and is not taken into consideration. The core is disassembled and cleaned using a three-stage cleaning process. A glass bead blast is used as well as high- and low-pressure chemical cleaning.

Some parts are always replaced, such as bearings or other wear items. These are removed and scrapped. Other parts are inspected to assess their potential for re-use. Experienced inspectors assess parts against criteria set in conjunction with the OEMs. This decision is made by taking measurements of the item and assessing the amount of wear it has experienced. This can be used to estimate the amount of life remaining in the part. For these products, there are no parts at all that are never replaced.

Some of the smaller parts are removed from the core and sent through a separate cleaning and inspection procedure. The main parts are placed in a tray together. An inspector uses a computer-based system to establish the part numbers of the replacement 
parts that will be required for the unit and uses the system to generate a stores order for them. It is at this point the failed parts are removed and scrapped.

All the replacement parts that are used are supplied by the OEMs or OEM-approved suppliers. Parts are never repaired. It would be possible for non-OEM parts to be used, but then the remanufactured gearbox would not be allowed to carry a full OEM warranty.

Once assembled, the unit is put through a testing procedure developed in conjunction with the OEM. The gearboxes are run both with and without load and analysed for noise and operation. Acceptable limits are set in conjunction with the OEM. One hundred percent of the units produced are inspected in this way.

Those units that fail this procedure are sent for rework by the operative who was responsible for assembling the unit.

\section{ClutchCo}

ClutchCo supplies 1,300 types of clutches used in cars in the UK and Europe. Half of these models, by part number, come from remanufacturing, and half are new imports, coming from China. The remanufactured clutches account for half the product lines but only $20 \%$ of sales volume. This strategy of using remanufacturing to supply lower volume items allows the company to hold less stock of slower moving parts at the same time as allowing it to have full market coverage. Thus, the imported clutches account for $80 \%$ of the total clutch sales, and these are cheaper. ClutchCo accepts that its remanufacturing area may now be running at a loss; however, it estimates this cost to be less than the cost of keeping the large stocks of slow moving parts that would be necessary if it was to import them from China.

As an independent remanufacturer, ClutchCo has had little cooperation from the OEMs of the products it remanufactures. This is despite the apparent legal obligation of the OEMs to cooperate. (The End of Life Vehicles Directive requires all information required for the correct and environmentally sound treatment of end-of life vehicles to be made available to authorised treatment facilities by vehicle manufacturers and component producers [6]. In order to establish their processes for remanufacturing, ClutchCo purchases OEM clutches and reverse-engineers them. They have found this to be a more effective method than obtaining information from the OEMs directly. None of the clutches that are remanufactured by ClutchCo are supplied to OEM manufacturers.

After the cores arrive at the plant they are sorted. They are identified by part type, against approved samples, and are inspected visually for any obvious damage that would make them unusable. The main fault inspectors are looking for is excessive wear to clutch diaphragms. Excessive wear would mean that the reassembled clutch would be unlikely to last a full second life. After inspection, the cores are formed into production batches and are stored in the warehouse.

When required, cores are collected from the warehouse and washed using a caustic solution. Sometimes the clutch diaphragm is tested before disassembly. The cover of the clutch is removed to facilitate access and all parts are cleaned in order to make them appear as new. Inspection of the clutch's component parts is carried out. Parts are worked upon or scrapped as necessary. 
The clutch is then reassembled and tested for clamp load and clearance. Clutches that fail this test are reworked. Finally each clutch is ink-jet sprayed with its part number and batch code.

PCCo

The mission of PCCo is to extend the life of office equipment. They offer a wide range of services ranging from collection and auditing of unwanted equipment to the supply and installation of refurbished equipment. The majority of the work undertaken is to dispose of used IT equipment. Where possible, they do this through remanufacture and resale of the equipment.

Items that are deemed to be unmarketable are separated from rest of the load of incoming equipment and are sent directly to a recycler. At the time of study, this included 15" CRT monitors.

The remaining items are sent to the remanufacturing facility. On arrival, a batch number is allocated to the equipment, and a unique tracking number is given to each piece of equipment. Information regarding the type of equipment, manufacturer and model number is stored against the tracking number at this stage.

The batch is then sent to the workshop where it is processed. Equipment is connected to a network which automatically audits and tests it. The network stores data about the equipment, carries out data erasure in accordance with the UK government standards and creates a record of the wipe. Software is used to carry out a fault diagnosis of the equipment.

The majority of equipment is found to be working. The exact amount varies depending on its source, but the average is similar to the $80 \%$ figure quoted for Germany by Steinhilper [37]. A visual inspection is made, and the equipment is cleaned as necessary.

Information collected during the diagnostic 'bench' test is used in order to determine the potential for remanufacturing each item of the equipment. This is restricted by value, functional state and age. A triage principle is used to sort the equipment into three streams. These are 're-use', where the computer is reused without further treatment, 'recycle', where the computer is sent for materials recovery and 'process further', where the faults with the computer are not known but it may be possible to reuse after further operations. Diagnostic information, collected during the bench test, is then used to estimate the parts and labour cost of processing each item of equipment according to its individual requirements.

If the decision is made to process an item further, then the item is disassembled and an investigation is made into the cause of the equipment failure. Once the cause is identified, this module or part is replaced with a working one, and the equipment is reassembled An electrical safety test is carried out then each computer is packaged for sale and shipping.

\section{CompCo}

CompCo remanufactures between 1,400 and 1,700 computers per month. The vast majority of these are desktop computers, but they also process a smaller number of laptop computers. CompCo works on a not-for-profit basis and provides computers to 
educational establishments and NGOs in various locations throughout the developing world. The standard processing lead time is 2 weeks, and stock does not spend much time in the warehouse.

Computers are sorted at source as much as possible. Only high specification, working machines are accepted. Computers that are found not to work or to be the wrong specification are recycled with the cost, plus a premium charge for disposal, borne by the donor. This is meant to incentivise donors to supply the required machines, rather than use CompCo for general disposal.

Computers arrive at the warehouse in an unknown state. Information on the condition of the computers is sometimes given by the donor, but it usually turns out to be inaccurate. For this reason, the decision making about the suitability of a machine for remanufacture is made entirely on the basis of a visual inspection, the model of the computer and an estimation of its age. This is used to estimate the length of usable lifetime a computer will have once it is fully working. If it is decided that a computer is not suitable for remanufacturing it is sent for part recovery and/or materials recycling.

During the next stage of the process, the data wiping, the machine specifications are found using a diagnostic software. Based on this, it is decided if the computer is suitable for reuse as it is or if it requires upgrading or part replacement. If the equipment cannot be used, then it is sometimes cannibalised for spare parts.

No standard part replacements are made but computers are cleaned and tested for safety before they are shipped.

\section{Generic inspection procedures in remanufacturing processes}

It was found that the processes undertaken by the remaining cases were very similar to those described above. Electronic product inspection and remanufacture was carried out using the same steps at CompCo and PCCo whereas mechanical product inspection was carried out using the same steps at GearCo and ClutchCo. All of the processes were found to have certain stages in common.

The flow charts that were generated during each of the case studies were compared, and common stages of the process were extracted. Focussing particularly upon inspection processes, a name was selected for each stage of inspection that was common across the cases. This led to the creation of a model that could be described as a 'common ground' or 'consensus' model which applies across the cases. This could form the basis of a generic inspection procedure.

The model was shown graphically using the IDEF0 modelling standard. The IDEF0 standard was used in preference to other modelling techniques such as flow charts because it allows decomposition, is easy to understand due to the simple graphics that are used, is precise and can be used with data abstraction. This is a particularly useful feature in the creation of a generic process diagram such as the one described in this paper. Mechanism arrows were not included in the diagrams as these are often specific to each company. A company might choose to use a machine to carry out a given inspection whereas another might carry out the process using skilled labour. It is the activity or job that must be carried out that was of interest for this research rather than the exact way it was carried out in a specific company. For a full discussion of the benefits of the IDEF0 standard in process modelling, see [45] or [46]. 


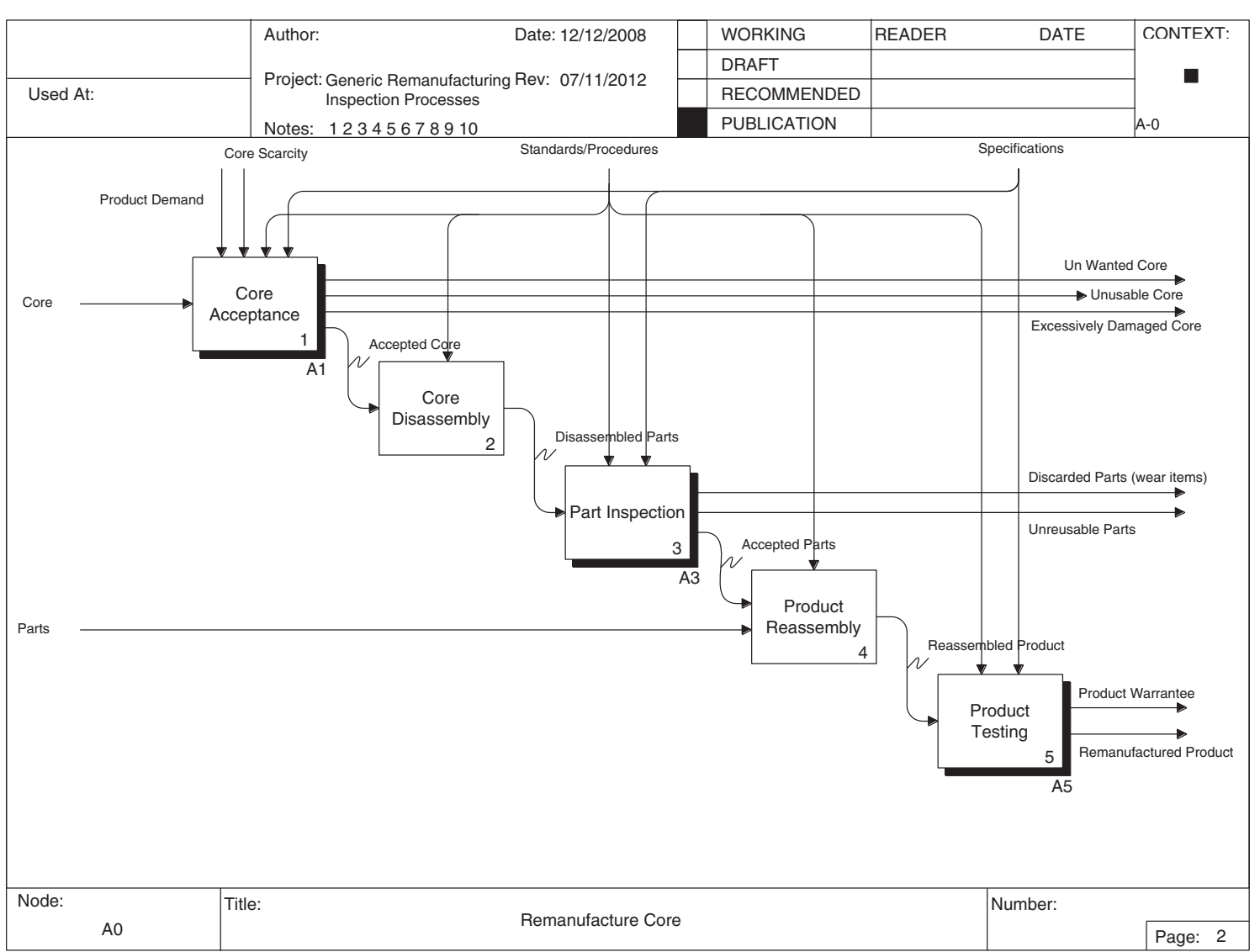

Figure 1 IDEF0 diagram of generic remanufacturing process. 
Figure 1 shows the generic remanufacturing process that was observed in the cases. It can be seen that three key areas of inspection were found. Each was carried out at a different stage in the remanufacturing processes. These were identified as follows:

- core acceptance;

- part inspection; and

- final product testing.

The different stages of inspection have different objectives. Due to these different objectives, the physical inspection processes themselves are different. The objective of core inspection and testing is to remove cores that will be uneconomical or impossible to remanufacture, accepting only those thought to be viable. This improves the reliability of the population of items that are produced and ensures that cores that are uneconomical to remanufacture do not enter the process. This process is often carried out by a triage-type process. This was referred to as 'scratch and sniff' by an expert in the automotive remanufacturing industry.

The second stage of inspection is carried out once the core has been disassembled. Part inspection and testing aims to remove non-reusable components from the product in order to increase its reliability once it is reassembled. These parts may be nonreusable because they have already failed or because they are likely to fail within the next working lifetime of the product. This is typically done using a visual inspection for wear, but in other processes, measurements are made using lasers, and some parts are tested for performance.

The final product inspection stage is carried out to ensure that the products are in full working order before they are shipped. Products that fail this stage are reworked before being retested and sold. This process is often similar to typical final product testing in traditional forward manufacturing. Products are operated and their performance assessed to ensure they are within acceptable limits.

All the inspection and testing procedures are carried out in order to increase confidence in the ability of a product to perform throughout its second life. Without these procedures, it would be difficult to ensure the quality of the products produced and to offer full 'as new' guarantees as required for remanufactured products. This could potentially lead to a lack of consumer confidence in remanufactured products and excessive guarantee costs to the remanufacturer.

The effect of the three stages of inspection was to remove from the process those items that were of less value either because of requiring more work or being more likely to fail in service. In some cases, these items were not discarded but were disassembled in order to reuse good components.

\section{Core acceptance}

Cores are usually inspected as soon as they arrive at the remanufacturing facility or at the first stage in the process once items are taken from storage for use. This is the process which Loomba proposes should be used more to reduce remanufacturing costs [47]. Figure 2 shows the details of how this inspection is carried out. 


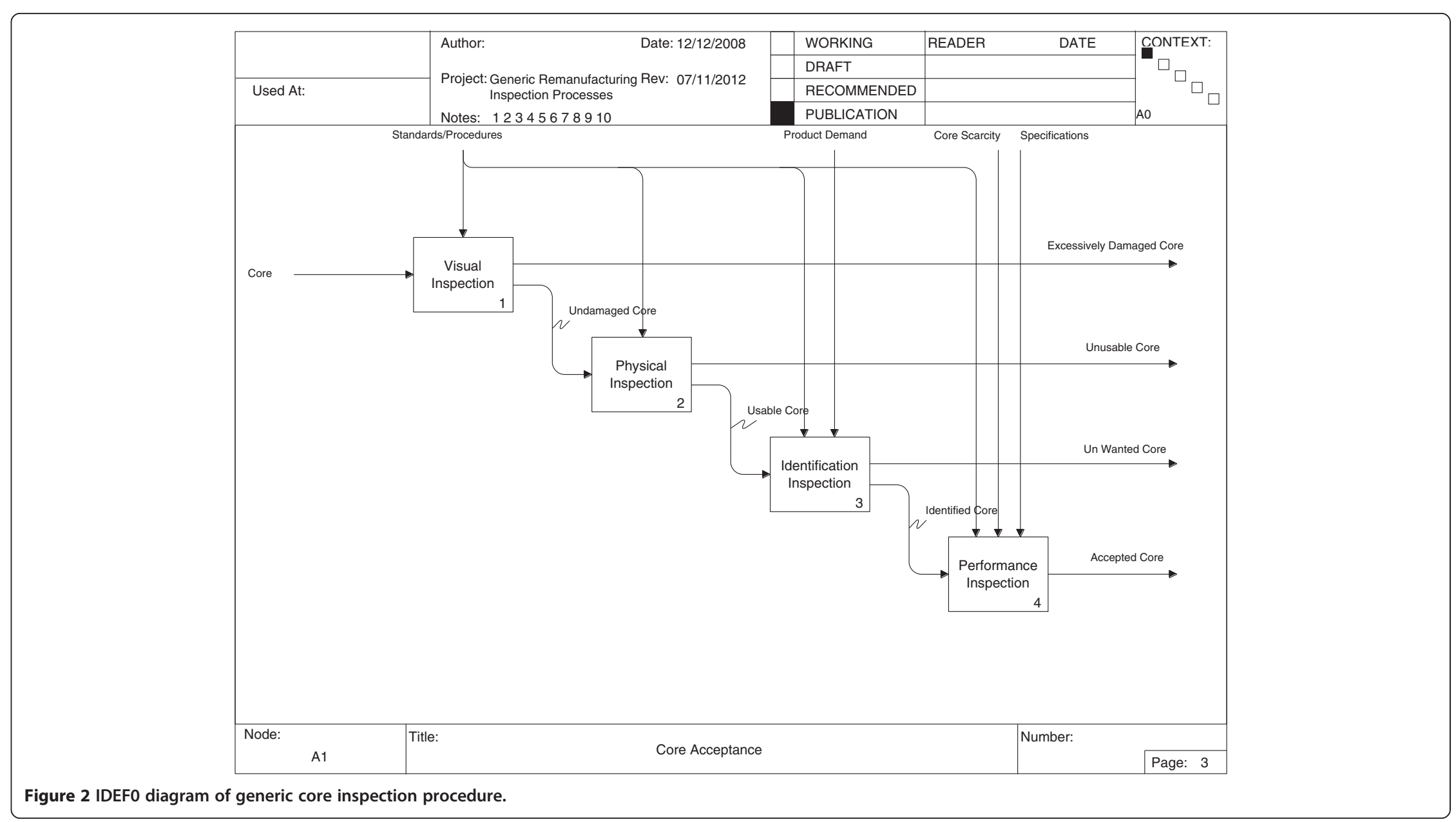


The figure shows the four main tasks that were identified in the core acceptance procedure. The first is a visual inspection. This is carried out simply through looking at a core and deciding whether it has obvious major damage which would make it unusable. An example of products that would be rejected at this stage would be products that have been crushed during transit to the remanufacturing facility. All the cases used visual inspection with the aim of removing excessively damaged items from the process. However, the case of CompCo suggests visual inspection could be entrusted to suppliers given certain conditions.

Cores that have no obvious signs of major damage are subjected to the second test in the procedure. This has been described in Figure 2 as the physical inspection. Again this is done manually, but the actual process varies depending on the core being inspected. For automotive components, two main methods are commonly used. The first is to attempt to rotate any part of the product that should normally move and the second to smell electrical components to test for burn out. Cores that fail this test are sent for recycling and/or disposal.

The third stage of the process is to identify the part type and part number of the core. This is used to estimate the demand for and value of the product after it has been remanufactured. Cores for which there is no demand are disposed of at this stage. It may seem counter-intuitive that the identity of the part is only investigated at this stage of the process. One might assume that it would be sensible to identify a component before any analysis is made of its potential for remanufacture. The reason that was given for the identification belonging to this stage of the process was the relative difficulty of the first three stages of inspection. To carry out a visual and physical inspection, known by CoreCo as 'Scratch and sniff' is a very quick process whereas identifying a core through the use of part numbers and expertise can be relatively time consuming. This was stated by CoreCo as being particularly the case for steering columns which do not typically carry part numbers and must be identified by highly trained operatives. This identification operation allows inventory to be managed for future use.

The fourth and final task within the core acceptance procedure aims to assess the performance of the core. This is usually done using test rigs specifically designed for the procedure. The standards the product must meet are set by OEMs, industry bodies, international standards or the remanufacturing firm itself. The aim of this process is twofold: firstly, to establish whether the core is economical to process and secondly to establish whether the finished product is likely to conform to specifications once it has been remanufactured. This is another opportunity to remove unusable items from the process, occurring once simpler checks have been carried out.

\section{Part inspection}

Once cores have passed the core inspection and testing procedure, they are sent for disassembly and further inspection. After disassembly and cleaning, they are passed to the second set of inspections and tests. The diagram for this process is shown in Figure 3.

It can be seen from the diagram that some of the tasks carried out on the parts are similar to those carried out on the core. Firstly each part is identified. If, according to company procedures, it is a part that is always replaced, then it is discarded 


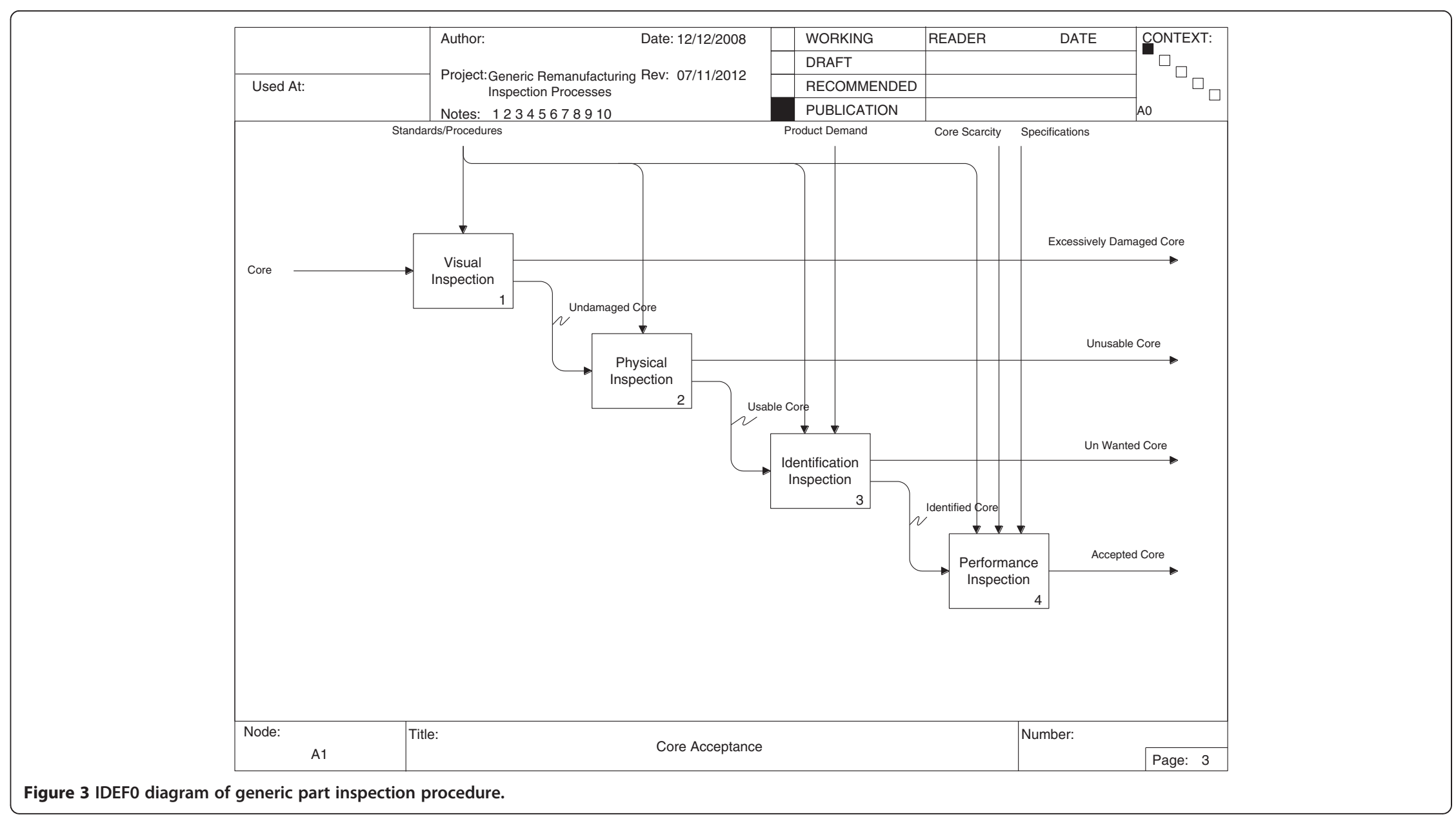


immediately. These are usually wear components, such as bearings and bushes, and are often the reason for previous user discarding the product. When parts may be replaced, identification is clearly necessary.

Parts that could be reused are sent through a functional inspection process. Typical activities in this process include measurement and leakage testing. If they are found not to conform to required specifications, whether for functional or safety reasons, then they are either discarded or reconditioned. It was found that this decision was mainly made on the basis of cost and lead time.

During the case study interviews, it was stated that it is often quicker to recondition a part in house than it is to order a new one to be made. A similar comment is made by Depuy et al. [48]. This is especially the case when small numbers of parts which are not mass produced are concerned. In practice, this seems to make the reconditioning of parts a part of the inspection process, wherein the components are inspected until they are accepted or failed. This contrasts to manufacturing, where parts are normally processed until they are finished, with inspection as a final operation, and makes the remanufacturing process more similar to craft work or 'fitting'. After reconditioning, parts are inspected once more for performance in order to ensure they meet requirements.

It was observed at CompCo that no physical disassembly was ever performed, so physical parts were never assessed or replaced. In this case, the disassembly consisted only of removing data and reassembly only or installing of new software. Nevertheless, this case was regarded as remanufacturing (rather than re-use) since the confidence gained from the inspections and tests allowed the company to offer OEM level specification and warranty.

Once the quality of parts has been accepted, additional parts, either new or reconditioned from other sources, are used to replace the ones discarded in the previous inspection stage. The product is then reassembled. Once it is reassembled, it is passed to the third and final stage of the inspection procedure, the product testing stage.

\section{Product testing}

It can be seen that functional inspection is the key part of this inspection and testing process. This is the final stage at which the reliability of the final product can be estimated and/or ensured. The diagram for this process is shown in Figure 4. The process carried out and the standards applied during the functional inspection are different for each product. In the case of OEM-approved remanufacturers, these are developed with involvement of the OEM for the product concerned. This ensures satisfactory operation.

Products that fail the functional inspection are reworked and retested before they are sold. It would seem logical that products would be sent back to the disassembly process to be disassembled (where this involves a dedicated area or workplace). However, in practice, it was found to be more common for the product to be sent back to the person who reassembled it. GearCo stated that this was done because the reassembly operative would be likely to know what the cause of the fault would be. Thus, the corrective actions are again more closely linked to the inspections than in manufacturing. 


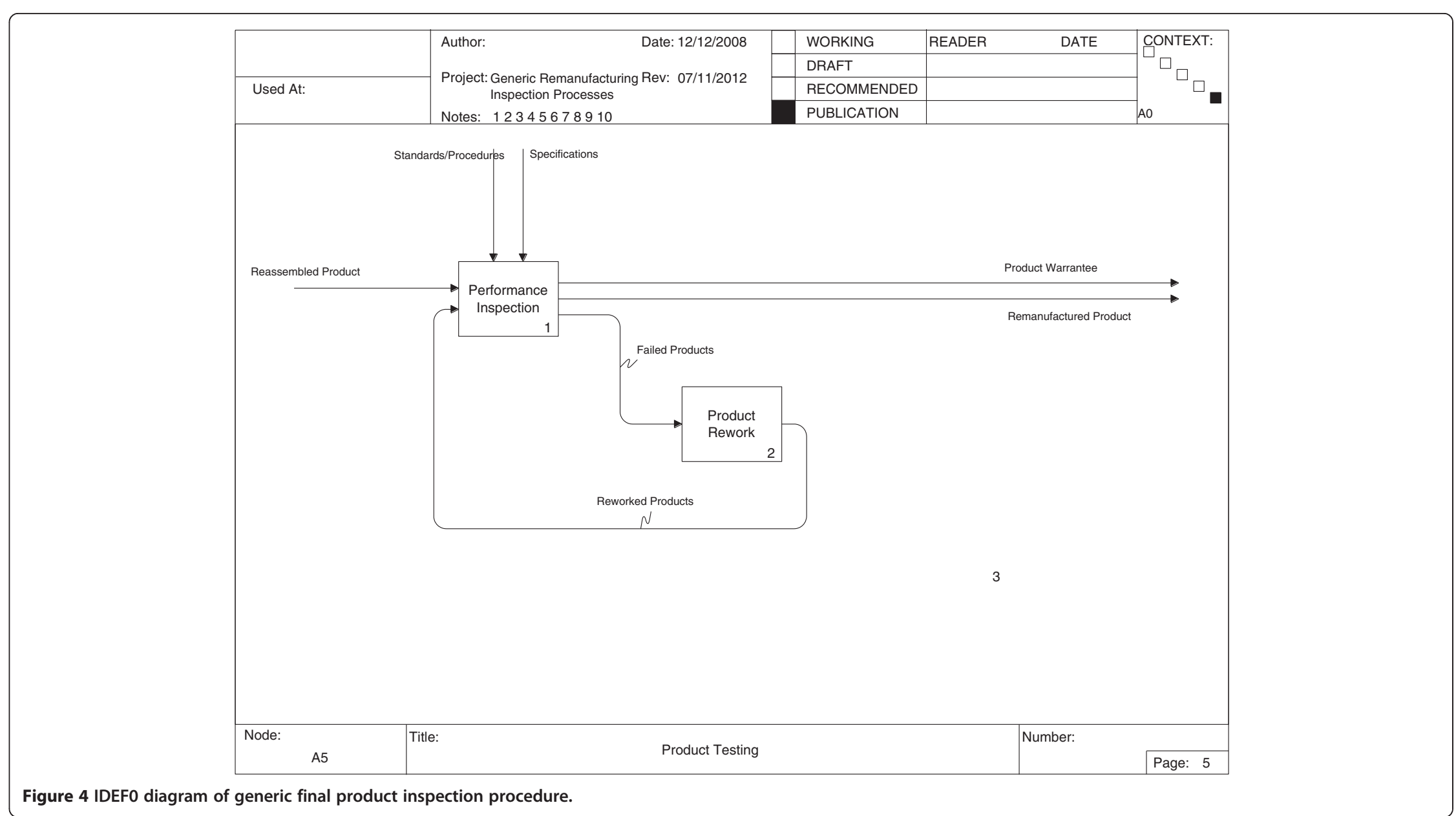




\section{Discussion}

There appear to be two motives for inspection: (1) to remove unreliable individuals from the population and (2) to show that enough work has been done to achieve the required level of performance.

By removing unreliable individuals, the confidence in the remanufactured products is raised. However, this does not mean that all products require all the possible inspection stages. The processing that units go through will be identical for all the units that are not obviously damaged or in a doubtful condition. It is simply not necessary to know the details of the state of a unit. By performing the simplest and cheapest inspection operations first, the parts that are removed by these operations do not undergo the more expensive or time-consuming activities. This kind of inspection could be termed inbound inspection and consists of identification and some kind of simple assessment of condition. Inbound inspection is not concerned with the units as individuals but as feedstock. This applies at the core level and at the part level.

By showing that enough work has been done, the second type of inspection becomes part of a cycle where products go through a loop of testing, re-work, re-assembly, testing until the performance is found to be adequate. At first glance, this looks like trying to 'inspect quality into a product' which Deming was against (Dodge quoted in Deming 1982 [49]). However, Deming was looking at the whole system of manufacturing, in which quality depends on product design and production system design. In this instance, it seems better to think of this cycle of inspection as adjustment or tuning of the product. For example, balancing is a normal requirement in the manufacture of rotating machines, and the activity of balancing continues until acceptable balance is achieved. The balancing cannot improve the quality of the components, but it provides correct performance of the product. This could be termed outbound inspection and is concerned with the units as individuals, providing specific attention to the condition of each one. This applies at the part level and at the final product.

It was found that, in most cases, inspection was carried out three times during the remanufacturing process. Although Brent and Steinhilper state that it is always necessary to carry out $100 \%$ inspection during remanufacturing processes [40], these cases show that this does not mean all inspection operations are done on all items. The key thing to consider is if the inspection will actually lead to any decisions being made. It is possible that without disassembling a core, sufficient information cannot be gathered to make a confident decision about the functionality of the part. In other cases, due to a shortage of cores, all items have to be disassembled anyway so there is no need to carry out the first inspection.

Some authors propose that information from green port systems or from the user directly can be used in place of some of the stages of inspection. These are particularly applicable to the core acceptance procedure but rely on accurate and reliable information being available. One way to ensure it is available is to lease rather than sell equipment to the customer. It has been widely reported that this has been a particularly successful method for Xerox Corporation.

In the case studies, no major differences between the way OEM and non-OEM remanufactures operated their inspection procedures were observed. OEM remanufactures are thought of as having fewer problems sourcing cores and information with regards to the design of the products. There is no doubt that these make the 
remanufacturing business easier to run; however, no impact was observed on the inspection procedures of the companies that were studied.

This section of the paper has presented a generic inspection procedure developed from case studies carried out with companies carrying out remanufacturing operations.

The following section will give details of how the models of the procedure that have been presented in this section were validated in order to gain confidence in their generalisability.

\section{Model validation}

Validation of the model was carried out using a group of six companies contacted through a consultancy firm specialising in remanufacturing. The consultancy firm in question is also responsible for running the UK government-funded Centre for Remanufacturing and Reuse. A visit was made to each of these remanufacturers during the late part of 2008, and a presentation was given describing the model, its origin and its potential uses. The practitioners were then asked to fill in a short questionnaire. Responses were recorded on paper. Interviewees were invited to comment on how they thought the models should be altered, where applicable, to show their processes more correctly.

Table 2 shows the companies that were studied for the validation stage of this research.

It can be seen that the cases were from a variety of industries which remanufacture a large variety of products. WasteCo is relatively new to remanufacturing, and at the time of writing, its processes were undergoing extensive development.

Interviewees were asked to respond to the statement "The processes that have been described in the presentation closely match what is done in our process." Each interviewee was asked to place their opinion on a six-point Likert scale. A score of 1 indicated that the interviewee strongly disagreed with the statement, and a score of 6 indicated that the interviewee strongly agreed. There was no neutral point. Table 3 shows the responses of the interviewees for each of the cases.

It can be seen that all the respondents agreed that the model closely matched what was done in their processes: 1 case strongly agreed, 5 agreed and 1 case slightly agreed. Overall, there was agreement among validation case interviewees to the view that the models matched what was done in their respective processes.

\section{Conclusions}

This work has identified the inspection operations used in nine case studies. The activities were grouped into a generic or common-ground model structured into three

Table 2 Case studies used for validation

\begin{tabular}{lcc}
\hline Company identifier & Product & Electronic/Mechanical \\
\hline CompressorCo & Compressors & Mechanical \\
VacCo & High vacuum pumps & Both \\
WasteCo & Televisions (also processes all types of WEEE) & Electronic \\
FlightCo & Aerospace flight control units & Mechanical \\
TonerCo & Toner cartridge & Mechanical \\
AltCo & Rotating automotive electrics & Mechanical \\
\hline
\end{tabular}


Table 3 Validation results

\begin{tabular}{|c|c|c|c|}
\hline $\begin{array}{l}\text { Company } \\
\text { identifier }\end{array}$ & Role of interviewee & $\begin{array}{l}\text { Remanufacturing volume units/ } \\
\text { month }\end{array}$ & $\begin{array}{l}\text { Close match to } \\
\text { process } \\
\text { (1 to } 6 \text { Likert) }\end{array}$ \\
\hline VacCo & $\begin{array}{l}\text { Global support manager } \\
\text { remanufacturing }\end{array}$ & 4,300 & $\begin{array}{l}6 \text { (Strongly } \\
\text { agree) }\end{array}$ \\
\hline WasteCo & Chairman & 4,000 & 5 (Agree) \\
\hline CompressorCo & Marketing admin & 200 & 5 (Agree) \\
\hline FlightCo & Quality manager & 2 to 3 & $\begin{array}{l}4 \text { (Slightly } \\
\text { agree) }\end{array}$ \\
\hline TonerCo & Production manager & 700 & 5 (Agree) \\
\hline AltCo & Managing director & 10,000 & 5 (Agree) \\
\hline
\end{tabular}

main stages: core acceptance, part inspection and final product testing. The model was subsequently assessed for its general applicability by representatives of a further six remanufacturing companies. The key contribution of this paper is a deeper understanding of the role inspection plays within remanufacturing processes. It can be used by practitioners to design a plan for remanufacturing their products, and it can be used by researchers as a framework for further research. It shows clearly where inspection technology may benefit the industry and how.

Another key finding was that in contrast to forward or traditional manufacturing, sample inspection is not usually used in remanufacturing processes. The state of the cores entering the system varies widely, each therefore needs to be inspected at the core level, part level or both to ensure that the components that are remanufacture are of suitable quality. One hundred percent inspection is potentially not necessary at the final product stage; however, this is almost always done. A possible reason for this is to increase confidence in remanufactured products.

The cases provide some insight into the use of inspection. Core acceptance procedures aim to remove unusable cores from the process, and the simplest inspections are used first so that most cores are rejected using the cheapest inspection procedure. Identification inspection is not generally the first activity in this stage since it can be time consuming. Functional inspection is generally left until last as it would be uneconomical to carry out this test on cores that could be rejected by cheaper tests. Core acceptance ensures, as far as possible, that only useful items proceed to the next stage, thus reducing the work required at subsequent stages, and removing problem items from the process, thereby improving the reliability of the population of items.

Part inspection is used to identify those parts that need replacing and to assess and recondition others. At this stage, there is a transition from accepting/rejecting items entering the process to specific assessment of individual items and the work required by each.

The final product inspection stage also sees products as individuals, the work done being tailored to achieving the correct performance from each unit. The activities of re-work and adjustment are only carried out on those units made from good cores, with new or reconditioned parts that have been re-assembled and from which fully acceptable performance can be expected.

The model that has been presented, although based on a limited set of cases, provides a structure that can be used to plan future remanufacturing operations. Some questions for the management of remanufacturing operations could be derived as follows: as 
operations managers might find these hard to answer, they may also be thought of as research questions.

\section{Core acceptance}

- What are the criteria for accepting a unit as a useable core (rather than as a source of parts or materials)?

- Which of these criteria can be most readily identified by the simplest inspection techniques? These should be carried out before the more complex, expensive or resource-intensive inspections.

- What are the relative advantages of using an item for remanufacture compared with the value of the parts it contains?

\section{Part inspection}

- Is dismantling necessary to confirm the acceptable condition of parts? Electronic components (such as in the IT cases) could be assessed by functional tests of the final product.

- What is the trade-off between the cost and energy saving of re-using a part compared to its expected reliability? If an item is part worn, its lifetime (and the lifetime of the product) can be assessed and related to the cost of a new part. Safety- and performance-critical parts may be replaced as a matter of policy without the need for inspection.

- What are the relative benefits and costs of re-conditioning parts in-house, subcontracting the reconditioning or making or purchasing new items?

- What are the inventory ramifications of storing large numbers of used parts?

\section{Final product testing}

- What degree of inspection and testing is required considering a product has been made up from known good parts?

- What is the relationship between assembly and adjustment for a particular product family? Should the adjustment form part of the same operation?

It is to be hoped that the models presented can be developed both by practitioners designing and managing remanufacturing operations and by researchers making further investigations in the area. Some research questions arising from this work are the following:

- Does the framework of core acceptance, part inspection and final product inspection apply across all types of remanufacturing operations?

- What activities may be added or deleted for particular technologies or market situations?

- What is the potential for incorporating remanufacturing activities into conventional manufacturing facilities? 
The key contribution of this paper is a tool which can be used for further investigation into the area of inspection in remanufacturing processes within academia and consultancy. It also provides a framework to aid companies in the development of new remanufacturing processes.

\section{Competing interests}

The authors declare that they have no competing interests.

\section{Authors' contributions}

ME carried out the research and wrote the first and subsequent drafts of the paper. SC supervised the research work and case studies and reviewed, made suggestions and alterations to sections of the paper. Both authors read and approved the final manuscript.

\section{Acknowledgements}

The authors wish to thank the many industrial representatives who allowed their operations to be studied and who contributed to the research.

Received: 14 February 2013 Accepted: 28 June 2013

Published: 26 July 2013

\section{References}

1. Errington, M, Childe, SJ: The Need for Inspection in Remanufacturing Operations. In: The Third World Conference on Production and Operations Management, Tokyo, Japan (2008)

2. Rooker, L, Benn, H: Climate Change Act 2008. HMSO, London (2008)

3. Richard, CD, Walter, Y: Encircling the peak of world oil production. Nat. Res. Res. 8, 219-232 (1999)

4. Bentley, RW: Global oil \& gas depletion: an overview. Energy Policy 30, 189-205 (2002)

5. EU: Directive of The European Parliament and of The Council on Waste Electrical and Electronic Equipment (WEEE). European Parliament, Brussels (2003)

6. EU: Directive of The European Parliament and of The Council on End-of Life Vehicles. European Parliament, Brussels (2000)

7. EU: European Parliament and Council Directive on Packaging and Packaging Waste. European Parliament, Brussels (1994)

8. EU: Council Directive on Batteries and Accumulators Containing Certain Hazardous Substances. European Parliament, Brussels (1991)

9. Jayaraman, V, Guide, VDR, Srivastava, R: A closed-loop logistics model for remanufacturing. J. Oper. Res. Soc. 50, 497-508 (1999)

10. Hammond, R, Amezquita, T, Bras, B: Issues in the automotive parts remanufacturing industry - a discussion of results from surveys performed among remanufacturers. (1998). Accessed 19 July 2013

11. Guide, VDR, Muyldermans, L, Van Wassenhove, LN: Hewlett-Packard company unlocks the value potential from time-sensitive returns. Interfaces 35, 281-293 (2005)

12. van Nunen, JAEE, Zuidwijk, RA: E-enabled closed-loop supply chains. Calif. Manage. Rev. 46, 40-54 (2004)

13. Maslennikova, l: Xerox's approach to sustainability. Interfaces 30, 226-233 (2000)

14. Johnson, MR, Wang, MH: Planning product disassembly for material recovery opportunities. Int. J. Prod. Res. 33, 3119 (1995)

15. Feldmann, K, Meedt, O, Trautner, S, Scheller, H, Hoffman, W: The "green design advisor": a tool for design for environment. J. Electron. Manuf. 9, 17 (1999)

16. Rose, CM, Ishii, K: Product end-of-life strategy categorization design tool. J. Electron. Manuf. 9, 41 (1999)

17. Bufardi, A, Gheorghe, R, Kiritsis, D, Xirouchakis, P: Multicriteria decision-aid approach for product end-of-life alternative selection. Int. J. Prod. Res. 42, 3139-3157 (2004)

18. Guide, JV, Daniel, R, Souza, GC, van der Laan, E: Performance of static priority rules for shared facilities in a remanufacturing shop with disassembly and reassembly. Eur. J. Oper. Res. 164, 341-353 (2005)

19. Guide, VDR: Scheduling using drum-buffer-rope in a remanufacturing environment. Int. J. Prod. Res. 34, 1081 (1996)

20. Goldratt, EM: The goal: beating the competition. Hounslow, Creative Output (1986)

21. Chung, C-J, Wee, H-M: Short life-cycle deteriorating product remanufacturing in a green supply chain inventory control system. Int. J. Prod. Res. 129, 195-203 (2011)

22. Richter, K: Pure and mixed strategies for the EOQ repair and waste disposal problem. OR Spektrum 19, 123-129 (1997)

23. Kondoh, S, Salmi, T: Strategic decision making method for sharing resources among multiple manufacturing/ remanufacturing systems. J. Remanuf. 1, 1-8 (2011)

24. Konstantaras, I, Skouri, K, Jaber, MY: Lot sizing for a recoverable product with inspection and sorting. Comput. Ind. Eng. 58, 452-462 (2010)

25. Nenes, G, Panagiotidou, S, Dekker, R: Inventory control policies for inspection and remanufacturing of returns: a case study. Int. J. Prod. Econ. 125, 300-312 (2010)

26. Uzsoy, R: Production planning for companies with product recovery and remanufacturing capability. In: Proceedings of the 1997 IEEE International Symposium on Electronics and the Environment, 1997 (ISEE-1997), San Francisco, 5-7 May 1997, pp. 285-290. IEEE, New York (1997)

27. Spengler, T, Schroter, M: Strategic management of spare parts in closed-loop supply chains- a system dynamics approach. Interfaces 33, 7-17 (2003) 
28. van der Laan, E, Salomon, M, Dekker, R: An investigation of lead-time effects in manufacturing/remanufacturing systems under simple PUSH and PULL control strategies. Eur. J. Oper. Res. 115, 195-214 (1999)

29. Guide, JV, Daniel, R, Srivastava, R: An evaluation of order release strategies in a remanufacturing environment. Comput. Oper. Res. 24, 37-47 (1997)

30. Guide, VDR, Jayaraman, V, Srivastava, R: The effect of lead time variation on the performance of disassembly release mechanisms. Comput. Indust. Eng. 36, 759-779 (1999)

31. Guide, VDR, Srivastava, R: Inventory buffers in recoverable manufacturing. In: Proceedings of the 28th Annual Meeting of the Decision Sciences Institute Atlanta. Georgia USA 1-3, 1405-1407 (1997)

32. Peng, ZY, Zhong, DY: Optimization model for closed-loop logistics network design in manufacturing and remanufacturing system. In: Zhong, DY (ed.) International Conference on Service Systems and Service Management, Chengdu, 9-11 June 2007, pp. 1-4

33. Blackburn, JD, Guide Jr, VDR, Souza, GC, Van Wassenhove, LN: Reverse supply chains for commercial returns. Calif. Manage. Rev. 46, 6-22 (2004)

34. Ray, S, Boyaci, T, Aras, N: Optimal prices and trade-in rebates for durable, remanufacturable products. Manuf. Serv. Oper. Manag. 7, 208-228 (2005)

35. Xiaochen, S, Yancong, Z, Yuling, N, Guangwei, S, AGS: Optimal Control for a Remanufacturing Reverse Logistics System under Buy-Back Policy. In: Yancong, Z ISDA '06 Sixth International Conference on Intelligent Systems Design and Applications 2006, vol. 1, pp. 1197-1202. IEEE, Washington (2006)

36. Guide, VDR, Van Wassenhove, LN: The reverse supply chain. Harv. Bus. Rev. 80, 25-26 (2002)

37. Steinhilper, R: Remanufacturing: The Ultimate Form of Recycling. Fraunhofer IRB, Stuttgart (1998)

38. Goldberg, LH: Green Electronics / Green Bottom Line: Environmentally Responsible Engineering. Woburn, Butterworth-Heineman (2000)

39. Nagel, C, Meyer, P: Caught between ecology and economy: end-of-life aspects of environmentally conscious manufacturing. Comput. Ind. Eng. 36, 781-792 (1999)

40. Brent, AC, Steinhilper, R: Opportunities for remanufactured electronic products from developing countries: hypotheses to characterise the perspectives of a global remanufacturing industry. In: Steinhilper, R (ed.) IEEE AFRICON Conference in Africa, Gaborone, vol. 892, pp. 891-896. IEEE, Piscataway (2004)

41. Voss, C, Tsikriktsis, N, Frohlich, M: Case research in operations management. Int. J. Oper. Prod. Manag. 22, 195-219 (2002)

42. Meredith, J: Building operations management theory through case and field research. J. Oper. Manag. 16, 441-454 (1998)

43. Eisenhardt, KM: Building theories from case study research. Acad. Manage. Rev. 14, 532 (1989)

44. Ijomah, WL, Childe, SJ: A model of the operations concerned in remanufacture. Int. J. Prod. Res. 45, 5857-5880 (2007)

45. Aguilar-Savén, RSRS: Business process modelling: review and framework. Int. J. Prod. Res. 90, 129-149 (2004)

46. Ang, CL, Luo, M, Gay, RKL: Knowledge-based approach to the generation of IDEFO models. Comput. Integr. Manuf. Syst. 8, 279-290 (1995)

47. Loomba, APS, Nakashima, K: Enhancing value in reverse supply chains by sorting before product recovery. Prod. Plan. Control 23, 205-215 (2011)

48. Depuy, DW, Usher, JS, Walker, RL, Taylor, GD: Production planning for remanufactured products. Prod. Plan. Control 18, 573-583 (2007)

49. Deming, WE: Out of the Crisis. MIT, Cambridge (1982)

doi:10.1186/2210-4690-3-7

Cite this article as: Errington and Childe: A business process model of inspection in remanufacturing. Journal of Remanufacturing 2013 3:7.

\section{Submit your manuscript to a SpringerOpen ${ }^{\circ}$ journal and benefit from:}

- Convenient online submission

- Rigorous peer review

- Immediate publication on acceptance

- Open access: articles freely available online

- High visibility within the field

- Retaining the copyright to your article

Submit your next manuscript at $\boldsymbol{~ s p r i n g e r o p e n . c o m ~}$ 